\title{
Validation of the Italian version of the Burn Specific Health Scale-Brief
}

\author{
Lucia Sideli $^{a, *}$, Angela Di Pasquale ${ }^{b}$, Alessia Prestifilippo ${ }^{a}$, Anna Benigno ${ }^{b}$, \\ Alice Bartolotta ${ }^{a}$, Chiara Rita Cirrincione ${ }^{a}$, Daniele La Barbera ${ }^{a}$ \\ a Department of Experimental Biomedicine and Clinical Neuroscience, Section of Psychiatry, University of Palermo, \\ Palermo, Italy \\ ${ }^{\mathrm{b}}$ Operative Unit of Plastic Surgery and Burn Therapy, Civico and Benfratelli Hospital, Palermo, Italy
}

\section{A R T I C L E I N F O}

Article history:

Accepted 4 October 2013

Keywords:

Burns

Quality of life

BSHS-B

\begin{abstract}
A B S T R A C T
Introduction: A growing awareness of psychological and functional impairment due to burns have led to the development of specific instruments to evaluate Quality of Life in this population, such as the Burn Specific Health Scale - Brief (BSHS-B), whose psychometric properties have been consistently verified. The aim of this study was to translate the BSHS-B into Italian and to investigate its reliability and validity.

Methods: Translation procedures were carried out according to accepted standards. Internal reliability was assessed using Cronbach's alpha coefficient. Concurrent validity was evaluated through correlations between the BSHS-B and the Short-Form 36 Health Survey (SF-36), the Self-report Clinical Inventory (SCL-90), and the Body Uneasiness Test (BUT).

Results: The overall Cronbach's alpha value for the scale was 0.887 . Significant correlations were found between the Italian BSHS-B domains, the SF-36 subscales (Spearman's rho: 0.184-0.414), and several SCL-90 subscales (Spearman's rho: -0.173 to -0.477 ). Furthermore, the affect and relationship domain and the skin domain of the BSHS-B negatively correlated with the compulsive self-monitoring and depersonalization subscales of the BUT.

Conclusion: The Italian translation of BSHS-B has shown satisfactory internal consistency, criterion validity, and convergent validity, supporting its application in routine clinical practice as well as in international studies.
\end{abstract}

C) 2013 Elsevier Ltd and ISBI. All rights reserved.

\section{Introduction}

As the advances of medical and surgical techniques have increased survival rates after burns, there has been an increased focus on the psychological sequelae of burn trauma, in order to improve the psychological and functional adjustment of this clinical population. It is well known that both psychological and physical consequences of burns (including pain, scars, contractures, and amputations) account for mild to severe impairment and disability and significantly affect Health Related Quality of Life (HRQoL). Comparison with population controls and clinical groups demonstrated that burn patients perceived a lower overall life satisfaction and HRQoL that is influenced by specific physical and psychological factors such as heat sensitivity, impaired self-care, body image dissatisfaction, and changes in their social and working role [1]. Burn survivors show relevant and persisting problems in home and social integration, experience family difficulties and a lack of social support [2-4]. Furthermore, systematic

* Corresponding author at: Section of Psychiatry, Department of Experimental Biomedicine and Clinical Neuroscience, Via G. La Loggia, 1 , 90129 Palermo, Italy. Tel.: +39 916555170; fax: +39 916555165.

E-mail address: lucia.sideli@gmail.com (L. Sideli). 
reviews claim that nearly $28-33 \%$ of burn patients have not returned to any form of employment after 3 years post-burn $[5,6]$. Psychiatric complications are a major issue in victims of burn trauma: according to the literature, up to $65 \%$ of inpatients burn units experience a variety of psychiatric symptoms including drowsiness, confusion, sleep disturbances, depression, and anxiety [7,8]. Hyper-arousal, avoidance, and re-experiencing of the traumatic events are common symptoms, which often raise the clinical threshold for Acute and Post-Traumatic Stress Disorder (11-25\% in the first month post-burn) [1]. Moderate to severe depressive symptoms - such as grief, shame, and social withdrawal - are experienced by $17-33 \%$ of in-patients and prevalence of Major Depressive Disorder ranges from $4 \%$ during the hospitalization to $10 \%$ in the year following discharge [9].

In light of these findings, post-burn HRQoL assessment contributes to improving out-patient aftercare service by recognizing individuals at a higher risk for developing psychological and psychiatric problems and by identifying physical, emotional, and social issues that may benefit from multi-disciplinary rehabilitation programs $[10,11]$. In response to the lack of a specific tool to evaluate HRQoL in burn survivors, Blades et al. (1979) developed the original Burn Specific Health Scale consisting of 114 items, from which an abbreviated (BSHS-A) [12], a revised (BSHS-R) [13], and a brief version (BSHS-B) [14] were derived. Easiness to administration, sensitivity to burn-related issues, and excellent psychometric properties have made the BSHS the most widely used instrument in clinical practice and research in burn trauma $[15,16]$. BSHS-B has been translated into several languages including Korean, Chinese, and Persian [17-19], but not Italian. The aim of this study was to translate the BSHS-B into Italian and to investigate its reliability and validity.

\section{2.}

\section{Methods}

The study project was approved by the clinical team of the Operative Unit of Plastic Surgery and Burn Therapy of the Civico and Benfratelli Hospital of Palermo (Italy). Possible participants were approached by psychologists and medical residents within 6 months from their admission. All the participants were informed about the study's aims and procedures and then provided their written informed consent. Participants' anonymity was maintained throughout data collection and data analysis. Psychologists and medical residents distributed the self-report questionnaires to the patients and, when needed, assisted them in providing written answer to the questions.

\subsection{Participants and settings}

Study participants were adult burn patients (18-65 years) consecutively recruited from the Operative Unit of Plastic Surgery and Burn Therapy of the Civico and Benfratelli Hospital of Palermo (Italy) from 2010 to 2012. Patients were excluded if they were not fluent in Italian, presented either severe perceptual disabilities or mental retardation, or referred any diagnosis or treatment for major psychiatric or neurological disorders.

\subsection{Measures}

\subsubsection{The Burn Specific Health Scale-Brief (BSHS-B)}

The Burn Specific Health Scale-Brief (BSHS-B) is a widely used instrument to assess quality of life in burn patients [14]. The scale consists of 40 items encompassing nine subscales: simple abilities ( 3 items), hand function (5 items), work (4 items), body image (4 items), heat sensitivity (5 items), treatment regimens (5 items), affect (7 items), interpersonal relationships (4 items), and sexuality (3 items). Each item describes a particular task or experience that subjects are asked to evaluate on a scale from 0 (extreme) to 4 (not at all). A recent factor analysis $[11,20]$ showed that, with the exception of work, all the above subscales can be grouped into three domains: the function domain (simple abilities and hand function), the skin sensitivity domain (body image, heat sensitivity, and treatment regimen), and the affect and relationship domain (affect, interpersonal relationship, and sexuality). Mean scores were calculated for each of the nine subscales and for the three domains. Consistently with other HRQoL scales, lower scores of the BSHS correspond to a worse quality of life.

Translation procedures were carried out according to accepted standards [21,22]. The original English version was forward-translated by two independent translators, an English translator and a psychiatric nurse fluent in English, who agreed on a final Italian translation. This first Italian version was independently back-translated in English by another translator and by a psychologist fluent in English with experience in HRQoL research, who, in turn, agreed on a final English back-translation. The Italian translation and the English back-translation were then reviewed by a multi-disciplinary committee composed by a professor of Psychiatry, a psychologist with experience in burn care unit, a physician, and a psychologist. The English backtranslation was compared to the original version in order to detect any misinterpretation and ambiguity; the two versions were found to be reasonably similar. Furthermore, the Italian translation was compared to the original one to ensure conceptual equivalence and improve understandability. Minor amendments were made to the sexuality subscale: to render the question less embarrassing for patients, the item 21 was worded as "I feel frustrated because I cannot be sexually active (original: aroused) as I used to"; the item 23 was changed into "I no longer hug, hold the hand (original: hold), or kiss" as there is no real difference in the Italian language between hugging and holding. In addition, "tying shoelaces, bows..." in item 6 was modified in "tying shoelaces, necktie..." to provide another example of the same hand function. Eventually, a pilot study was conducted with 10 out-patients, using the probe method. Patients were asked whether they considered any of the items challenging, annoying, or irrelevant and were asked to put one item for each subscale in their own words. The Italian translation of BSHS-B showed adequate face validity.

\subsubsection{The Short-Form 36 Health Survey (SF-36)}

The SF-36 $[23,24]$ was included in the study protocol to evaluate criterion validity. SF-36 is the most widely used 
self-report questionnaire in the evaluation of the impact of a variety of diseases and treatments on HRQoL. The 36 items encompass eight subscales: (1) limitations in physical activities because of health problems (10 items); (2) limitations in usual role activities because of physical health problems (4 items); (3) limitations in usual role activities because of emotional problems (4 items); (4) bodily pain (2 items); (5) general mental health (psychological distress and well-being) (5 items); (6) limitations in social activities because of physical or emotional problems (2 items); (7) vitality (energy and fatigue) (4 items); and (8) general health perceptions (5 items). Subscale scores are transformed into a 0-100 scale, where lower scores refer to worse HRQOL.

\subsubsection{The Self-Report Clinical Inventory (SCL-90)}

The SCL-90 $[25,26]$ was administered to evaluate convergent validity. SCL-90 is a 90 -items questionnaire which is used to assess presence and severity of psychopathological symptoms in general medicine settings. Questions refer to symptoms that occurred during the previous week and are grouped into nine subscales: obsessivity-compulsivity (10 items), interpersonal sensitivity (9 items), depression (13 items), anxiety (10 items), rage-hostility (6 items), somatization (12 items), phobic anxiety (7 items), paranoid ideation (6 items), and psychoticism (10 items). All items are scored on a 0 (not at all) to 4 (severely) scale and averaged to get subscales scores. Higher scores correspond to severe or highly frequent symptoms.

\subsubsection{The Body Uneasiness Test (BUT)}

The BUT $[27,28]$ was also administered to evaluate convergent validity. The BUT is a self-report questionnaire that is used to evaluate body image dissatisfaction in the general population. The 34 items cover five subscales: weight phobia (8 items), body image concerns (9 items), avoidance (6 items), compulsive self-monitoring ( 6 items), and depersonalization (5 items). For the purpose of this study, the first subscale (weight phobia) was not computed. Items are scored on a 0 (never) to 4 (always) scale and higher scores correspond to higher dissatisfaction.

\subsubsection{Demographic}

In addition to the above, socio-demographic and clinical information was collected for every patient.

\subsection{Psychometric documentation}

\subsubsection{Reliability}

The internal consistency of the Italian BSHS-B was assessed for each sub-scale and domain, as well as for the overall scale.

\subsubsection{Validity}

Concurrent validity was evaluated as criterion validity and convergent validity. For criterion validity, SF-36 was chosen as the gold standard measure for HRQOL and correlations with the Italian BSHS-B domains were analyzed. Since it is recognized that a poor HRQOL after-burn is associated with psychopathological symptoms (particularly, anxiety and depression) and body image dissatisfaction, correlations between SCL-90, BUT, and the Italian BSHS-B domains were analyzed to evaluate convergent validity.

\subsection{Data analyses}

Analyses were carried out by using SPSS ver. 18. Cronbach's alpha was calculated for each subscale, domain, and for the overall scale, to assess internal consistency. Spearman's correlation coefficient was used to evaluate convergent validity between the Italian BSHS-B domains and the SF-36, the SCL-90, and the BUT subscales. There was a limited amount of missing items in the Italian BSHS-B as well as in the questionnaires used for concurrent validity (less than $10 \%$ of missing values in each instrument). To calculate the Cronbach's alpha values, these items were excluded listwise. The same procedure was used to calculate the mean subscale scores of the BSHS-B and the other questionnaires.

\section{Results}

\subsection{Sample description}

Of 141 potential participants, 10 (7.1\%) were excluded from the study because of self-reported pre-burn psychiatric diseases. There were no differences between participants and nonparticipants in terms of gender, age, level of education, occupational status, total burn surface area (TBSA), presence of full-thickness burns, and presence of hand or face burns. The final sample consisted of 32 (24.4\%) in-patients and 99 (75.6\%) out-patients. Sixty-nine $(52.7 \%)$ of the participants were male, $73(55.7 \%)$ had 8 years of education, 90 (68.7\%) were employed at the time of the injury, 35 (26.7\%) were unemployed, $6(4.6 \%)$ were students or retired. The mean age was 40.21 years $(\mathrm{SD}=12.33) .26(19.8 \%)$ subjects were victim of a job accident while 78 (59.5\%) were burnt at home, 12 (9.2\%) in the street, and $15(11.5 \%)$ in other places, such as in the countryside. The majority of burns were thermal injuries, 64 (49.0\%), 56 (42.7\%) were scalds while only 11 (8.3\%) were caused by chemicals. The mean TBSA was 16.80 (SD = 12.20), $81(61.8 \%)$ patients had either hand or face burns, and 17 (13.0\%) had full thickness burns.

\subsection{Reliability}

Cronbach's alpha coefficients for the Italian BSHS-B subscales ranged from 0.656 for sexuality to 0.905 for work. Coefficients for all three domains were higher than 0.8 . The overall alpha value for the scale was 0.887 (Table 1 ).

\subsection{Criterion validity}

Several significant correlations were found between the Italian BSHS-B domains, the work subscale, and the SF-36 subscales with Spearman's coefficients ranging from 0.184 to 0.414. Particularly, the skin involvement domain and the affect and relationship domains of the Italian BSHS-B were significantly associated with the bodily pain, mental health, social functioning, and general health of the SF-36. By contrast, the function domain correlated with the physical functioning and the physical role limitations subscales of the SF-36 (Table 2). 
Table 1 - Internal consistency reliability for the Italian BSHS-B.

\begin{tabular}{lccc} 
Italian BSHS-B & N & Items & $\begin{array}{c}\text { Cronbach's } \\
\text { alpha }\end{array}$ \\
\hline Total score & 121 & 40 & 0.887 \\
Function domain & 129 & 8 & 0.801 \\
$\quad$ Simple abilities & 130 & 3 & 0.713 \\
$\quad$ Hand function & 130 & 5 & 0.888 \\
Skin involvement domain & 126 & 14 & 0.837 \\
$\quad$ Body image & 130 & 4 & 0.739 \\
Heat sensitivity & 128 & 5 & 0.900 \\
$\quad$ Treatment regimens & 130 & 5 & 0.825 \\
Affect and relationship domain & 131 & 14 & 0.886 \\
$\quad$ Affect & 131 & 7 & 0.867 \\
Interpersonal relationships & 131 & 4 & 0.810 \\
$\quad$ Sexuality & 131 & 3 & 0.656 \\
Work & 128 & 4 & 0.905 \\
\hline
\end{tabular}

\subsection{Convergent validity}

The Italian BSHS-B overall score showed mild to moderate negative correlations with all the SCL-90 subscales but paranoid ideation, suggesting that the lower the QoL is, the higher the frequency and severity of psychopathological symptoms are. The lowest Spearman's rho coefficient was for obsessivity-compulsivity ( $r h o=-0.173, p=0.048$ ) while the highest was for depression (rho $=-0.477, p<0.001$ ). The SCL90 subscale had multiple correlations with the skin involvement and the affect and interpersonal relationship domain, while no correlation was found with the function domain.

Significant negative correlations were found between the BUT subscales and the skin involvement domain and the affect and relationship domain of the Italian BSHS-B, confirming the role played by body image dissatisfaction in

Table 2 - Griterion validity for the Italian BSHS-B: correlation with the SF-36 subscales (Spearman's rho coefficient).

\begin{tabular}{|c|c|c|c|c|}
\hline \multirow[t]{2}{*}{ SF-36 } & \multicolumn{4}{|c|}{ Italian BSHS-B } \\
\hline & $\begin{array}{l}\text { Function } \\
\text { domain }\end{array}$ & $\begin{array}{l}\text { Skin involvement } \\
\text { domain }\end{array}$ & $\begin{array}{l}\text { Affect and } \\
\text { relationship domain }\end{array}$ & $\begin{array}{l}\text { Work } \\
\text { subscale }\end{array}$ \\
\hline Physical functioning & $0.404^{* *}$ & 0.107 & $0.209^{*}$ & $0.202^{*}$ \\
\hline Physical role limitations & $0.278^{* *}$ & 0.108 & 0.165 & 0.414 \\
\hline Emotional role limitations & 0.028 & 0.046 & 0.097 & -0.054 \\
\hline Bodily pain & 0.146 & 0.376 & $0.212^{*}$ & $0.217^{*}$ \\
\hline Mental health & 0.121 & 0.274 & $0.238^{* * *}$ & $0.206^{*}$ \\
\hline Social functioning & 0.040 & $0.213^{*}$ & $0.184^{*}$ & 0.128 \\
\hline Vitality & 0.101 & 0.159 & $0.208^{*}$ & $0.285^{* *}$ \\
\hline General health & 0.065 & $0.204^{*}$ & $0.252^{* *}$ & 0.102 \\
\hline
\end{tabular}

Table 3 - Convergent validity for the Italian BSHS-B: correlation with the SCL-90 and the BUT subscales (Spearman's rho coefficient).

\begin{tabular}{|c|c|c|c|c|}
\hline \multirow[t]{2}{*}{ SCL-90 } & \multicolumn{4}{|c|}{ Italian BSHS-B } \\
\hline & $\begin{array}{l}\text { Function } \\
\text { domain }\end{array}$ & $\begin{array}{l}\text { Skin involvement } \\
\text { domain }\end{array}$ & $\begin{array}{l}\text { Affect and } \\
\text { relationship domain }\end{array}$ & $\begin{array}{c}\text { Work } \\
\text { subscale }\end{array}$ \\
\hline Obsessivity-compulsivity & -0.126 & $-0.226^{* *}$ & $-0.173^{*}$ & -0.067 \\
\hline Interpersonal sensitivity & -0.096 & $-0.224^{*}$ & $-0.298^{* * *}$ & -0.046 \\
\hline Depression & -0.156 & $-0.343^{* *}$ & $-0.477^{* *}$ & $-0.190^{*}$ \\
\hline Anxiety & -0.105 & $-0.282^{* *}$ & $-0.272^{* *}$ & -0.105 \\
\hline Rage-hostility & -0.165 & $-0.201^{*}$ & $-0.234^{* *+}$ & -0.011 \\
\hline Somatization & -0.140 & -0.200 & -0.092 & -0.105 \\
\hline Phobic anxiety & -0.151 & -0.154 & $-0.198^{*}$ & -0.142 \\
\hline Paranoid ideation & -0.037 & -0.130 & $-0.234^{* *}$ & 0.013 \\
\hline Psychoticism & -0.100 & -0.121 & $-0.350^{* * *}$ & -0.047 \\
\hline \multicolumn{5}{|l|}{ BUT } \\
\hline Body image concerns & -0.154 & -0.131 & $-0.226^{* *}$ & -0.052 \\
\hline Avoidance & -0.116 & -0.074 & -0.067 & 0.074 \\
\hline Compulsive self-monitoring & -0.085 & $-0.236^{* *}$ & $-0.280^{* *}$ & -0.016 \\
\hline Depersonalization & -0.151 & $-0.239^{* *}$ & $-0.240^{* *}$ & -0.089 \\
\hline
\end{tabular}


modulating post-burn quality of life. Specifically, both domains were related with the compulsive self-monitoring and depersonalization subscales, while the affect and relationship domain additionally correlated with the body concerns subscales (Table 3 ).

\section{Discussion}

The Italian BSHS-B showed good internal consistency, with Cronbach's alpha coefficients above 0.9 for the total score and above 0.8 for the three domains. Particularly, the overall scale coefficient of 0.89 demonstrated a good homogeneity of our translation that is slightly lower than the Chinese (0.97) and the Persian (0.95) translations $[18,19]$. In addition, all subscales but sexuality, presented Cronbach's alpha coefficients between 0.71 and 0.91. These results are consistent with the original paper [14] as well as with other translations of the BSHS-B $[18,19]$, which found that sexuality had a lower alpha value than the other subscales. Notably, both in the Persian and the Chinese adaptation sexuality alpha values were lower than 0.7 . However, it cannot be excluded that the lower alpha value was an effect of the amendments made to the translation of this subscale.

The correlation setween the Italian BSHS-B and the criterion measure, the SF-36, were in the expected direction and, largely, in the expected distribution: as indicated by Willebrand and Kildal [20], the function domain was significantly associated with the physical aspects of quality of life (i.e. physical functioning and physical role limitations subscales of SF-36), while the skin involvement and the affect and relationship domains correlated with the bodily pain and the mental aspects of HRQoL (social functioning, mental health, and vitality). This suggests that the Italian BSHS-B describes a construct of HRQOL that reasonably overlaps with that assessed by the SF-36.

On the other hand, these correlations were less strong than those expected from the previous study [20] evaluating the relationship between the BSHS-B domains and the SF-36 at 6 months post-burn (0.4-0.5). Similarly, another study [29] found moderate to strong correlations $(0.4-0.6)$ between the overall BSHS-B score and the SF-36 subscales in a sample of mainly ambulatory patients assessed at the same time interval. The discrepancies between our and their results should be better investigated by further studies. It might be influenced by different characteristics of the samples or might reflect a lack of power due to inadequate sample size.

By examining the relationships between the Italian BSHS-B and the symptoms subscales of the SCL-90, we observed that lower scores in the skin involvement and the affect and relationship domains were associated with more severe and frequent symptoms of depression, anxiety, interpersonal sensitivity, and hostility, and - to a minor extent - to severe symptoms of delusional ideation or hallucinations. By contrast, such a relationship was not found with the function domain and the work subscale. Associations between poor HRQoL at BSHS and anxiety and depression symptoms are well documented by the literature, both in the early and late course of burns. In the above mentioned paper by Willebrand and Kildal [20] the anxiety and depression score of the Hospital Anxiety and Depression Scale negatively correlated with the skin involvement and the affect and relationship domains and, less strongly, with the function domain and the work subscales. Furthermore, in a Korean sample of hospitalized burn patients assessed two months after the burn trauma, the Center for Epidemiologic Studies Depression Scale (CES-D) correlated with all BSHS-B subscales, particularly with affect, body image, treatment regimens and heat sensitivity [30]. Similarly, in another sample of Brazilian out-patients assessed within 1 year from injury, the Beck's Depression Inventory (BDI) showed strong correlations with the affect and body image domain and the interpersonal relationship domain of BSHS-R [31]. In both studies, simple abilities and work had the lowest correlations with depression. Compared to these three studies, we found similar negative correlations between depression, anxiety, and the BSHS subscales related to interpersonal relationship, affect, and body image. However, the magnitude of these relationships was lower than that observed by them. As per before, the different results might be influenced by different characteristics of the samples or insufficient power. Furthermore, it might be speculated that the weaker correlation between health-related quality of life, anxiety, and depression is due to the use of SCL-90, a generic instrument for assessing psychiatric symptoms, rather than the more specific HADS, CES-D, and BDI scales. Indeed, looking at the correlations between the SF-36 subscales and the anxiety and depression score of SCL-90 we found a similar effect size (ranging from -0.191 to -0.424 ).

With regards to body image dissatisfaction, we found that the skin involvement and the affect and relationship domains negatively correlated with the body concerns, compulsive selfmonitoring, and depersonalization subscales of the BUT, indicating that a poor HRQOL is associated with persistent worries, feelings of shame and embarrassment, and perception of self-estrangement or self-detachment. Previous studies showed that clinically significant body image dissatisfaction was associated with lower scores in both the mental and the physical subscales of SF-36 [32] and predicted psycho-social functioning at 12 months post-discharge, mediating the effect of gender, TBSA, and pre-burn quality of life [33].

In summary, the Italian translation of BSHS-B has shown satisfactory internal consistency, and acceptable criterion and convergent validity, supporting its application in routine clinical practice as well as in international studies. Nevertheless, the study presents several limitations such as the limited sample size and the heterogeneity of the sample, which is comprised of both in-patients and out-patients with various severities of burns. In addition, the short interval between the time of injury and the assessment might have artificially reduced the impact of burn on quality of life. Therefore, further studies are needed to confirm the psychometric properties of the Italian BSHS-B.

\section{Role of funding sources}

None.

\section{Contributors}

LS and DLB designed the study. ADP coordinated the data collection. $\mathrm{AB}, \mathrm{AP}, \mathrm{AB}$, and $\mathrm{CRC}$ administered and scored the 
questionnaires. LS undertook the statistical analyses and wrote the first draft of the paper. DLB methodologically revised the paper. All the authors contributed to and approved the final paper.

\section{Conflict of interest}

None.

\section{Acknowledgments}

We thank all the patients and all the members of the Italian BSHS-B study team who collaborated with this study. We are particularly grateful to Ms. F. Alferi, Ms. S. Cataldi, Ms. P. Enna, and Ms. N. Valenziano.

\section{R E F E R E N C E S}

[1] Esselman PC, Thombs BD, Magyar-Russell G, Fauerbach JA. Burn rehabilitation: state of the science. Am J Phys Med Rehabil 2006;85(4):383-413.

[2] Esselman PC, Ptacek J, Kowalske K, Cromes GF, Engrav LH. Community integration after burn injuries. J Burn Care Res 2001;22(3):221-7.

[3] Costa MCS, Rossi LA, Lopes LM, Cioffi CL. The meanings of quality of life: interpretative analysis based on experiences of people in burns rehabilitation. Rev Lat Am Enfermagem 2008;16(2):252-9.

[4] Elijah I, Edelman LS, Sabourin H, Dong L, Saffle JR, Cochran A. The social milieu of burn injury and recovery: using social capital as a framework for evaluating sex differences. J Burn Care Res 2008;29(1):123-9.

[5] Mason ST, Esselman P, Fraser R, Schomer K, Truitt A, Johnson K. Return to work after burn injury: a systematic review. J Burn Care Res 2012;33(1):101-9.

[6] Quinn T, Wasiak J, Cleland H. An examination of factors that affect return to work following burns: a systematic review of the literature. Burns 2010;36(7):1021-6.

[7] Klinge K, Chamberlain DJ, Redden M, King L. Psychological adjustments made by postburn injury patients: an integrative literature review. J Adv Nurs 2009;65(11): 2274-92.

[8] Patterson DR, Everett JJ, Bombardier CH, Questad KA, Lee VK, Marvin JA. Psychological effects of severe burn injuries. Psychol Bull 1993;113(2):362-78.

[9] Thombs BD, Bresnick MG, Magyar-Russell G. Depression in survivors of burn injury: a systematic review. Gen Hosp Psychiatry 2006;28(6):494-502.

[10] Van Loey NEE, Faber AW, Taal LA. Do burn patients need burn specific multidisciplinary outpatient aftercare: research results. Burns 2001;27(2):103-10.

[11] Willebrand M, Kildal M. A simplified domain structure of the burn-specific health scale-brief (BSHS-B): a tool to improve its value in routine clinical work. J Trauma Acute Care Surg 2008;64(6):1581-6.

[12] Blades B, Mellis N, Munster AM. A burn specific health scale. J Trauma 1982;22(10):872-5.

[13] Blalock SJ, Bunker BJ, DeVellis RF. Measuring health status among survivors of burn injury: revisions of the Burn Specific Health Scale. J Trauma 1994;36(4):508-15.

[14] Kildal M, Andersson G, Fugl-Meyer AR, Lannerstam K, Gerdin B. Development of a brief version of the Burn
Specific Health Scale (BSHS-B). J Trauma Acute Care Surg 2001;51(4):740-6

[15] Yoder LH, Nayback AM, Gaylord K. The evolution and utility of the burn specific health scale: a systematic review. Burns 2010;36(8):1143-56.

[16] Kildal M, Andersson G, Gerdin B. Health status in Swedish burn patients. Assessment utilising three variants of the Burn Specific Health Scale. Burns 2002;28(7):639-45.

[17] Son HG, Seo CH, Kim JH, Jang KU, Noh SY. Reliability and validity of a Korean version of the Burn Specific Health Scale-Brief (BSHS-B-K). J Korean Burn Soc 2005;8(2):127-36.

[18] Ling-Juan Z, Jie C, Jian L, Xiao-Ying L, Ping F, Zhao-Fan X, et al. Development of quality of life scale in Chinese burn patients: cross-cultural adaptation process of Burn-Specific Health Scale-Brief. Burns 2012;38(8):1216-23.

[19] Pishnamazi Z, Rejeh N, Heravi-Karimooi M, Vaismoradi M. Validation of the Persian version of the Burn Specific Health Scale-Brief. Burns 2013;39(1):162-7.

[20] Willebrand M, Kildal M. Burn specific health up to 24 months after the burn - a prospective validation of the simplified model of the Burn Specific Health Scale-Brief. J Trauma Acute Care Surg 2011;71(1):78-84.

[21] Bullinger M, Anderson R, Cella D, Aaronson N. Developing and evaluating cross-cultural instruments from minimum requirements to optimal models. Qual Life Res 1993;2(6):451-9.

[22] Guillemin F, Bombardier C, Beaton D. Cross-cultural adaptation of health-related quality of life measures: literature review and proposed guidelines. J Clin Epidemiol 1993;46(12):1417-32.

[23] Ware Jr JE, Sherbourne CD. The MOS 36-item short-form health survey (SF-36): I. Conceptual framework and item selection. Med Care 1992;30:473-83.

[24] Apolone G, Mosconi P, Ware JE. Questionario sullo stato di salute SF-36: manuale d'uso e guida all'interpretazione dei risultati. Milano: Guerini e Associati; 1997.

[25] Derogatis LR, Lipman RS, Covi L. SCL-90: an outpatient psychiatric rating scale - preliminary report. Psychopharmacol Bull 1973;9(1):13-28.

[26] Cassano G, Conti L, Levine J. SCL-90. In: Conti L, editor. Repertorio delle scale di valutazione in psichiatria. Firenze, Italy: SEE; 1999. p. 325-32.

[27] Cuzzolaro M, Vetrone G, Marano G, Garfinkel P. The Body Uneasiness Test (BUT): development and validation of a new body image assessment scale. Eat Weight Disord 2006;11(1):1-13.

[28] Cuzzolaro M, Vetrone G, Marano G, Battacchi MW. BUT, Body Uneasiness Test: a new attitudinal body image scale. Psichiatr Infanzia Adol 1999;66:417-28.

[29] Edgar D, Dawson A, Hankey G, Phillips M, Wood F. Demonstration of the validity of the SF-36 for measurement of the temporal recovery of quality of life outcomes in burns survivors. Burns 2010;36(7):1013-20.

[30] Roh YS, Chung HS, Kwon B, Kim GY. Association between depression, patient scar assessment and burn-specific health in hospitalized burn patients. Burns 2012;38(4):506-12.

[31] Ferreira E, Dantas RAS, Rossi LA, Ciol MA. The cultural adaptation and validation of the Burn Specific Health ScaleRevised(BSHS-R): version for Brazilian burn victims. Burns 2008;34(7):994-1001.

[32] Fauerbach JA, Heinberg LJ, Lawrence JW, Munster AM, Palombo DA, Richter D, et al. Effect of early body image dissatisfaction on subsequent psychological and physical adjustment after disfiguring injury. Psychosom Med 2000;62(4):576-82.

[33] Thombs BD, Notes LD, Lawrence JW, Magyar-Russell G, Bresnick MG, Fauerbach JA. From survival to socialization: a longitudinal study of body image in survivors of severe burn injury. J Psychosom Res 2008;64(2):205-12. 